\title{
Recurrence of astrocytoma of optic nerve after 48 years
}

\author{
JOAN MULLANEY, J. WALSH, W. R. LEE, AND J. H. ADAMS \\ From the National Ophthalmic Pathology Laboratory of Ireland, Royal Victoria Eye and \\ Ear Hospital, Dublin, and University Departments of Ophthalmology and Neuropathology, Glasgow
}

Hoyt and Baghdassarian (1969) and Spencer (1972), from comprehensive studies of the clinical and pathological features of optic nerve gliomas in childhood, concluded that these tumours are congenital and non-neoplastic and are often associated with neurofibromatosis. Although they may enlarge and cause symptoms in early life they tend to be clinically indolent and self-limiting. This does not apply to every case, however, and Spencer (I972) reported a benign optic nerve astrocytoma in an II-year-old boy in whom there were four recurrences in the subsequent 13 -year period.

Optic nerve gliomas in adults, on the other hand, are aggressive and often rapidly fatal. They may initially simulate optic neuritis, since they usually present acutely (Martin and Cushing, 1923; Sæbø, 1949; Mattson and Peterson, 1966; Hamilton, Garner, Tripathi, and Sanders, 1973; Hoyt, Meshel, Lessell, Schatz, and Suckling, 1973). A pilocytic astrocytoma with some anaplastic features in the optic nerve of a middle-aged patient is therefore of interest. The tumour appeared 48 years after the excision of a juvenile optic nerve glioma.

\section{Case report}

In 1925 a 4-year-old boy presented with a left proptosis and defective upward and outward movement of the eye. The exophthalmometer reading was $18 \mathrm{~mm}$ on the left and $15 \mathrm{~mm}$ on the right. The media were clear and secondary optic atrophy and venous congestion were observed. Radiological examination of the orbit and the Wassermann reaction were both negative. A Krönlein operation was performed and an optic nerve tumour removed by dividing the nerve close to the globe and to the optic foramen. The case was reported by Goulding (1927). The pathological findings were described as follows. 'On macroscopic examination a growth was adherent to the optic nerve and microscopic examination showed fibromatous tissue in which large areas were in a degenerate condition, as evidenced by feebler staining'. The slides are not now available.

In July 1973 the patient, then aged 52 years, presented with a history of gross left proptosis for many years and a large medial orbital mass (right eye $6 / 6$; left eye

Address for reprints: Joan Mullaney, Royal Victoria Eye and Ear Hospital, Adelaide Road, Dublin 2, Eire no perception of light). Radiological studies showed changes which suggested an old lateral orbital fracture. There was no evidence of neurofibromatosis. The left eye was enucleated and a large encapsulated retrobulbar tumour, filling the orbit, was removed. The chiasma was not involved. There was no evidence of recurrence 27 months after operation.

\section{PATHOLOGY}

The left eye measured $24 \times 23 \times 23 \mathrm{~mm}$. The optic nerve had been cut flush with the globe. The eye was diffusely atrophic and a temporal crescent was present at the disc. Microscopy showed an old healed keratitis with calcification, generalized optic atrophy, and gliosis and calcification in the region of the papilla. The optic nerve remnants contained sparse but identifiable nerve fibres in hyalinized tissue, the stump being partially covered by ectopic conjunctival epithelium (Fig. I). The mass in the orbit measured $4.3 \times 4.0 \times 3.8 \mathrm{~cm}$ and was apparently encapsulated. On section most of the tumour was solid and of a pinkish-beige colour but there were some small cysts and possible foci of necrosis (Fig. 2).

\section{HISTOLOGY}

Some parts of the tumour were composed of trabeculae of greatly elongated pilocytic cells many of which had abundant eosinophilic ectoplasm (Fig. 3a). Other areas, some surrounded by these trabeculae, were composed of oval or polyhedral cells containing central, slightly hyperchromatic nuclei (Fig. $3 b$ ); microcystic change was conspicuous in these areas. Throughout the tumour there was a dense but delicate stroma of collagen and reticulin, but in some parts glial fibrils predominated (Fig. 3c). There was also a dense collagenous capsule partly infiltrated by tumour cells. The amount of intercellular matrix varied but here and there it was aboundant. Discrete cysts were present but there was no frank necrosis. Blood vessels were very numerous but vascular proliferation of the type associated with highly anaplastic glial tumour was not identifiable. There was considerable nuclear pleomorphism throughout the tumour with the formation of some small multinucleate giant cells (Fig. $3 d$ ), but mitotic figures were not seen. There were several collections of lymphocytes within the tumour.

The appearances were interpreted as those of a pilocytic astrocytoma of the optic nerve which, over many years, had widely infiltrated the orbital tissue, thus 


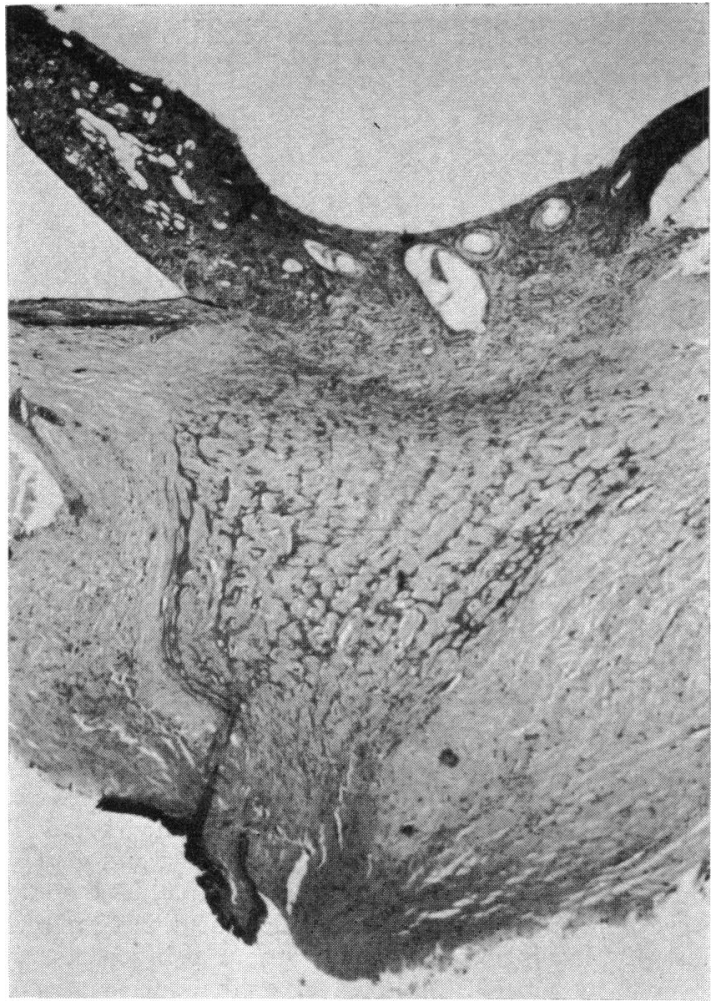

FIG. I Optic nerve and peripapillary retina of enucleated eye showing atrophic nerve and strip of conjunctival epithelium on posterior surface of specimen. Haematoxylin and eosin. $\times 25$

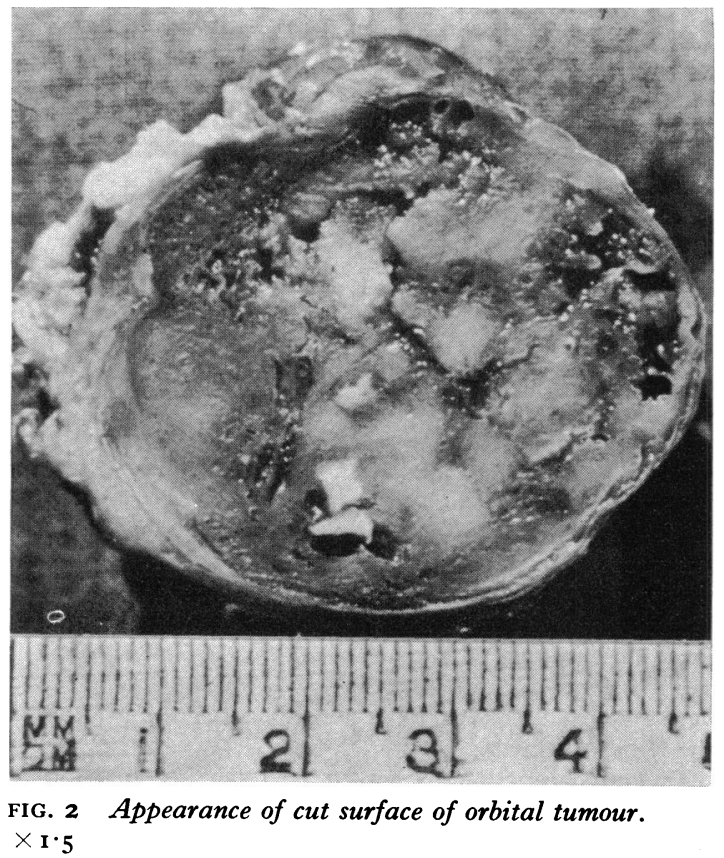

acquiring a rich mesenchymal stroma, and was now showing some signs of anaplasia. To confirm this diagnosis some of the formalin-fixed tissue was used for electron microscopy. The tissue was post-fixed in 3 per cent glutaraldehyde and I per cent osmium tetroxide and embedded in araldite. Ultrathin sections stained with uranyl acetate and lead citrate were examined in a Philips 300 electron microscope. The preservation of the cell ultrastructure was not ideal but useful information was obtained. Most of the tumour cells were of irregular size and outline (Fig. 4), occasionally multinucleate (Fig. $5 a$ ), and showed the characteristic feature of astrocytes in that the cytoplasm contained numerous filaments (70-80 $\mathrm{A}^{\circ}$ in diameter), often arranged in dense bundles (Fig. $5^{b}$ ). The nuclear chromatin was irregularly dispersed in these cells and the nucleolinema was coarse in the prominent nucleoli. Dense cytoplasmic inclusion bodies and dilated, rough endoplasmic reticulum containing granular material were identified in many of the cells. A few lipid histocytes were seen and other cells, which were either totally degenerate or could not be easily identified, were found between the tumour astrocytes. The capillaries available for examination did not show endothelial proliferation. The extracellular spaces contained collagen bundles, granular material, or debris which sometimes included circular electron-dense structures of about I $\mu \mathrm{m}$ diameter. These structures were very similar to those of degenerate lipid bodies.

\section{Discussion}

The information available about the nature of the original tumour (Goulding, 1927) is scanty, but most probably the 'growth adherent to the optic nerve' composed of 'fibromatous tissue and large degenerate areas' was a typical optic nerve glioma of childhood type. Examination of the enucleated eye showed undoubtedly that the orbital part of the optic nerve had been totally removed and that there was a large recurrent tumour in the orbit. The tumour had certain atypical features, presumably related to its duration and the extensive infiltration of the orbital tissues, but there was general agreement about its nature (see acknowledgement). The diagnosis of astrocytoma was confirmed by electron microscopy despite the fact that all of the tissue had originally been fixed in ro per cent formalin. This showed that the principal cells had ultrastructural characteristics similar to those described as tumour astrocytes in juvenile gliomas (Luse 1961; Anderson and Spencer, 1970), in an adult malignant glioma (Hamilton and others, 1973), and in an optic tract glioma and a glioblastoma multiforme (Raimondi, Mullan, and Evans, 1962). Malignancy is difficult to assess from cell ultrastructure, but the irregular dispersion of nuclear chromatin, the alterations in nucleolar architecture, and the presence of multinucleate cells are generally considered to indicate dedifferentiation. 

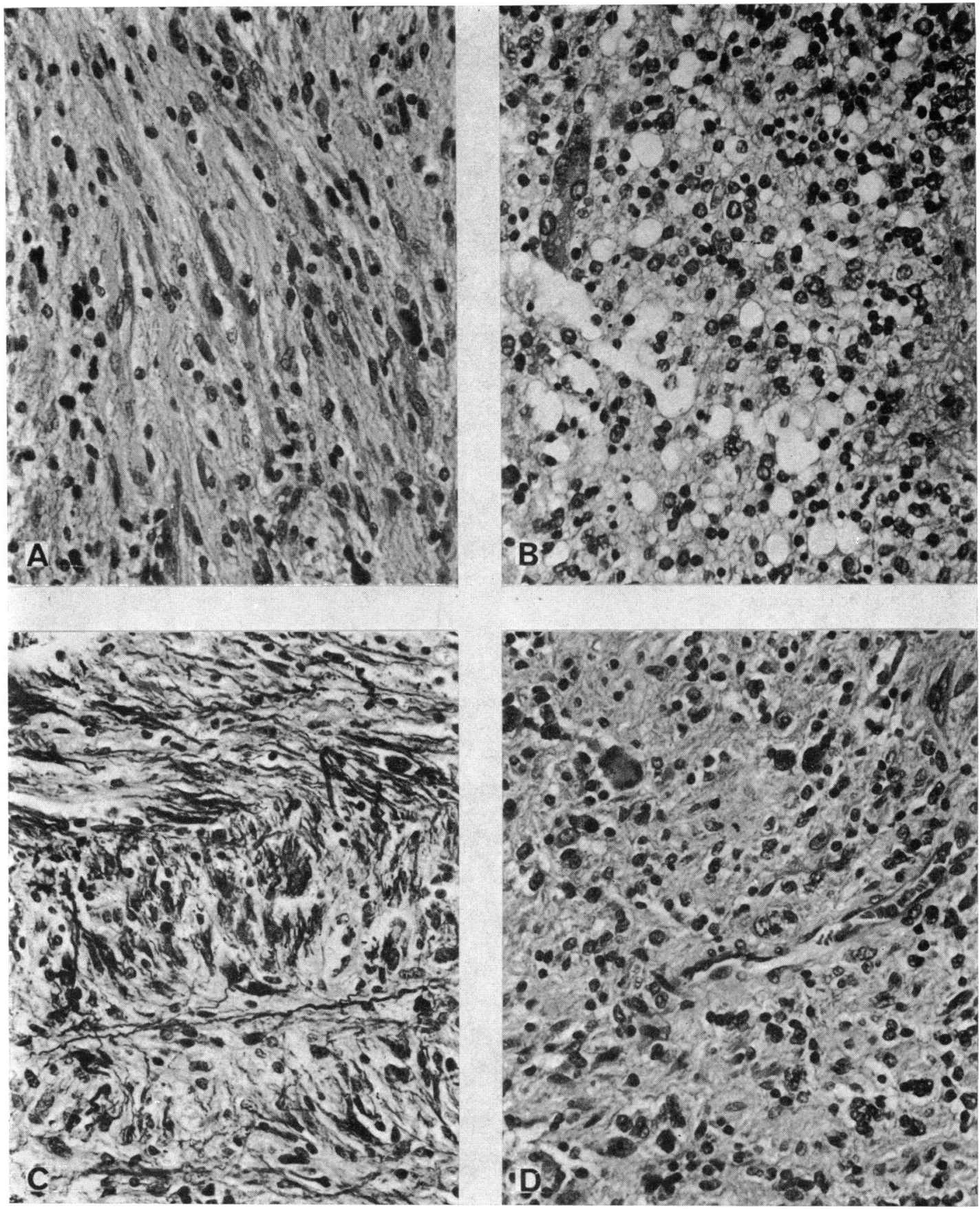

FIG. 3 Histological features of orbital tumour. (a) Area in which pilocytic cells predominate. Haematoxylin and eosin. $\times 250$. (b) Microcystic degeneration. Haematoxylin and eosin. $\times 250 .($ c) Conspicuous glial filaments. PTAH. $\times 250$. (d) Cellular pleomorphism and multinucleate cells. Haematoxylin and eosin. $\times 250$.

The tumour in this case therefore presents some unusual features, and it is of interest to speculate on its origin. The second growth could have arisen in gliomatous residue in the proximal optic nerve or, if excision had been complete, it could have been proliferation from a hamartomatous focus 


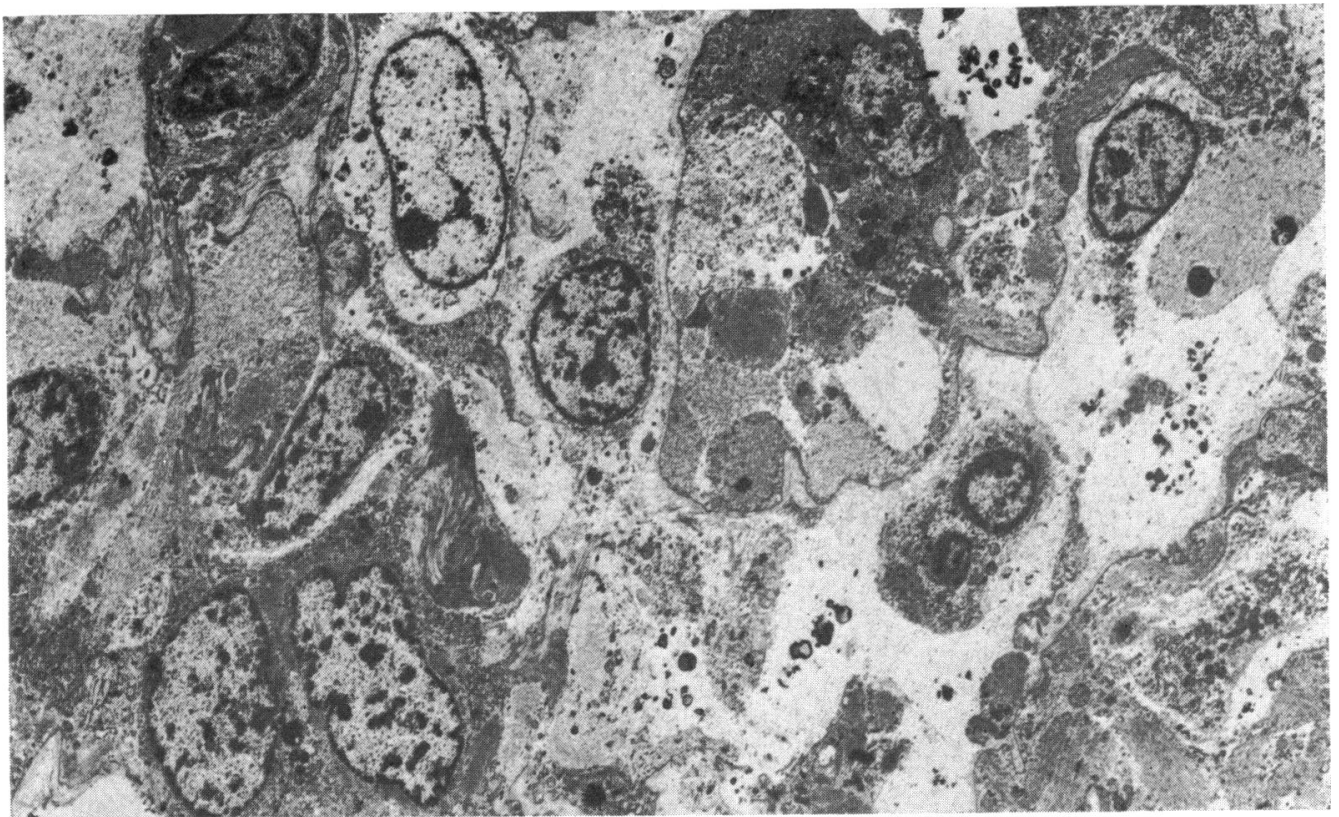

FIG. 4 Low-power electron micrograph showing irregular size and shape of tumour cells and uneven distribution of nuclear chromatin. $\times 2200$
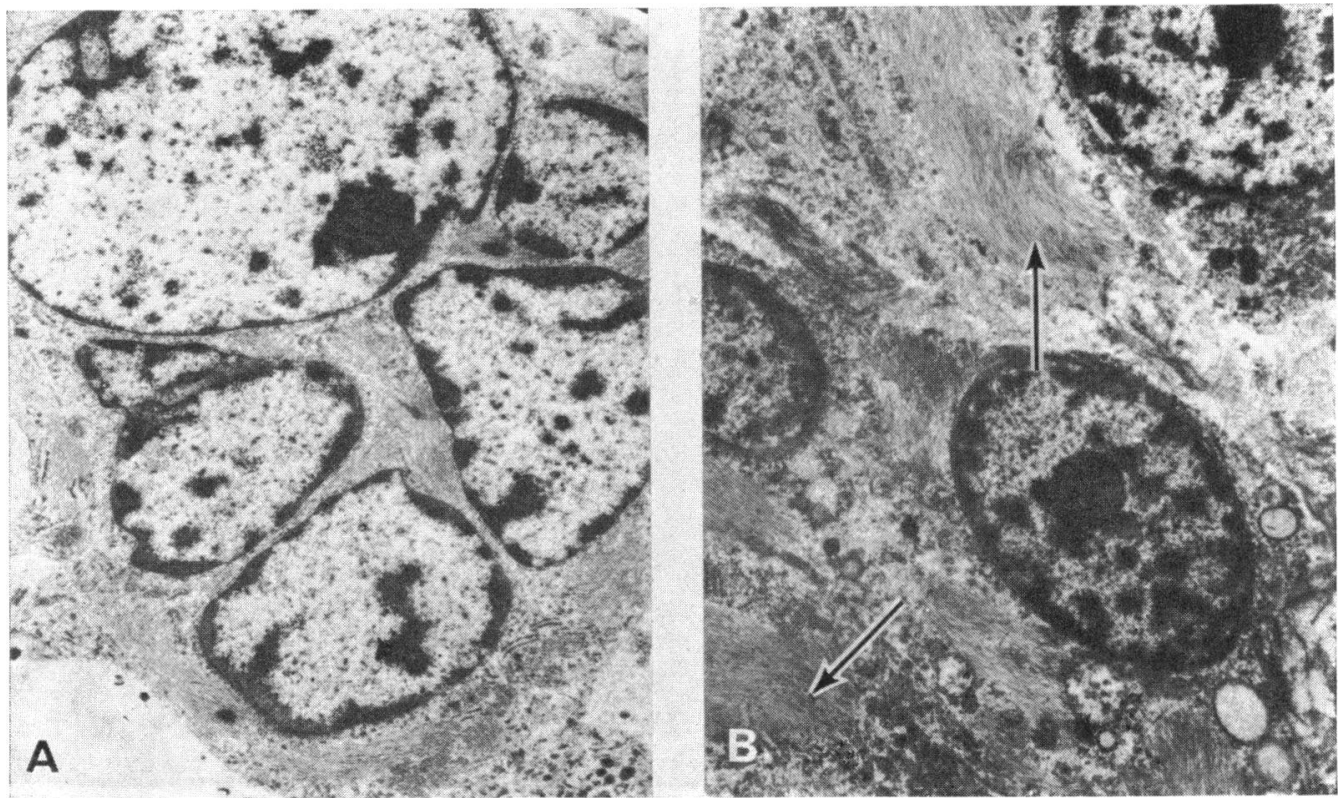

FIG. 5 Electron micrographs showing (a) multinucleate tumour cell, (b) prominent bundles of filaments (arrows) in cytoplasm of tumour cells. $\times 685^{\circ}$

in this part of the optic nerve. The latter would have been more likely if there had been clinical evidence of neurofibromatosis. Another potential. focus for neoplastic transformation could have been collateral hyperplasia of the glial cell com- ponent in the remaining optic nerve segment (Verhoeff, 1932; Anderson and Spencer, 1970). It is unfortunate that the primary tumour was not available for examination, because the case raises the possibility that juvenile gliomata can become 
malignant. The satisfactory subsequent course after secondary excision is atypical if the second optic nerve tumour is regarded as a glioma of the adult type, although long survival periods have been recorded in two adult optic nerve gliomas (Pagenstecher, 1902; Hoyt and Baghdassarian, 1969), which were first diagnosed at the ages of 30 and 25 years respectively.

\section{Summary}

A tumour presumed to be a juvenile glioma of the optic nerve was removed by a Krönlein procedure from a 4-year-old boy in 1925 . In 1973 a severe proptosis made it necessary to remove the atrophic eye and a large retro-ocular tumour. Histological examination, supported by electron microscopy, showed the second tumour to be an anaplastic pilocytic astrocytoma. The possible histogenesis and this unusual behaviour pattern are discussed.

We thank Professor Norman Ashton, Dr L. E. Zimmerman, and Professor Dorothy S. Russell for their comments on the orbital tumour, Mr R. Lester for technical assistance, and Miss Patricia Murphy for secretarial aid.

\section{References}

ANDERSON, D. R., and SPENCER, w. H. (1970) Arch. Ophthal., 83, 324

GOULding, H. B. (1927) Trans. ophthal. Soc. U.K., 47, 442

HAMIlTON, A. M., GARNER, A., TRIPATHI, R. C., and SANDERS, M. D. (r973) Brit. Y. Ophthal., 57, 253

HOYT, W. F., and BAGHDASSARIAN, s. B. (1969) Ibid., 53, 793

, MESHEL, L. G., LESSELl, S., SCHATZ, N. J., and SUCKLING, R. D. (1973) Brain, 96, I2 I

LUSE, S. A. (196r) f. Neurosurg., r9, 466

MARTIN, P., and CUSHING, H. (I923) Arch. Ophthal., 52, 209

mattson, r. H., and Peterson, e. W. (1966) F. Amer. med. Ass., 196, 799

PAGENSTECHER, R. A. (1902) Arch. Ophthal., 54, 300

RAIMONDI, A. J., MUllan, S., and EVANS, J. P. (1962) F. Neurosurg., I9, 73 I

ААВВØ, J. (1949) Brit. F. Ophthal., 33, 701

SPENCER, W. H. (1972) Trans. Amer. ophthal. Soc., 70, 490

VERHOEFF, F. H. (1932) 'Cytology and Cellular Pathology of the Nervous System', vol. 3, pp. 1029-1039.

Hoeber, New York 